\section{John Meyer Eisenberg, MD}

The recent untimely death of John Eisenberg, who was director of the United States Agency for Healthcare Research and Quality (AHRQ), leaves a void in the international healthcare research, quality, and patient safety movement. Until the last few weeks of his life John kept up a full workload, including writing an editorial with Gregg Meyer for the first issue of Quality and Safety in Health Care, ${ }^{1}$ a manuscript that turned out to be his last. John, despite his illness, insisted on corrections up to the deadline.

During John's tenure at AHRQ he established the agency as the premier quality and safety agency in the US. He developed extensive relationships with many countries and leaders in an effort to collaborate around the improvement of patient care and the reduction of patient harm from medical care around the world.

In an effort to understand this complex leader, we have invited several people who worked with John to share their personal reflections on what he meant to them and to help us appreciate a real visionary. This unique rashomoon will hopefully allow us to gain a better understanding of this great man.

Finally, John was proud of the journal QSHC and encouraged us to focus on patient safety as well as quality. Typical of many of his magic touches in life, he was also perhaps indirectly responsible for transformation of the journal $Q H C$ into $Q S H C$ as he introduced me to Richard Smith, editor of $B M J$, at a meeting that ultimately led to the launch of QSHC. A giant has passed.

John, we will miss you.

Paul Barach

Editor, QSHC; pbarach@airway.uchicago.edu

\section{Reference}

1 Meyer G, Eisenberg J. The end of the

beginning: the strategic approach to patien

safety research. Qual Safe Health Care

2002;11:3-4.

Passing of John Eisenberg, Testimony of Senator Bill Frist, US Senate hearings, 107th Congress, 15 March 2002

Mr President, John Eisenberg, director of the Agency for Healthcare Research and Quality, AHRQ, succumbed to a brain tumor this past Sunday. Although John had battled his illness for months, his death was a disturbing shock to many. He had done so much to improve health care in this nation, and I know there was much more he wanted to do. Still, John leaves a legacy-both professional and personal-so large that it cannot and will not be forgotten.

John Eisenberg was an outstanding public servant. He did not play partisan politics. Nor could he be corrupted by power. Simply put he was passionate about people. It was his mission to improve the quality of health care in America. He dedicated his life to that mission as the director of the Agency for Health care Research and Quality, as a founder of the Congressional Physician Payment Review Commission, and as a member and leader of countless other societies, associations, and institutes. For John, public service was more than his job; it was his life's calling which he answered with distinction and excellence.
I consider myself privileged to have worked with John Eisenberg for many years and on many issues. He taught me so much, not just about improving the quality of health care but about being a leader by transforming the way people think about issues and institutions. I know he had an impact on leaders in all branches of government, and men and women at all levels of government respected him. And as for the medical community: John was one of them. I have heard this often and, even with the event of his passing, I still hear it today.

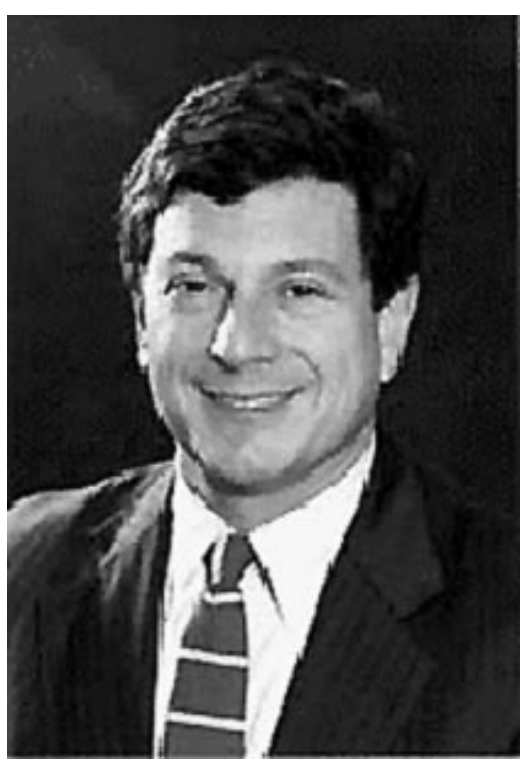

As a physician, John Eisenberg saved the lives of many. As a leader, he enhanced the lives of millions. As a friend, he touched the lives of us all. The largeness of his life and legacy will endure in our memories and warm our hearts for many years to come. John Eisenberg will be known as more than one of the good ones, but one of the best there ever was and ever will be.

Senator Bill Frist US Senate pbarach@airway.uchicago.edu

With the death of John Eisenberg the international field of healthcare quality and patient safety has lost a titan. John's leadership was inspirational, his influence on major policy makers was far reaching, his championship of the right of the consumer of health care to receive quality assured and safer services was tireless. Although John already had many admirers in Britain, the healthcare quality collaboration between the UK and the US governments cemented a unique bond between him and the leading figures in healthcare quality in this country. The US/UK collaboration was sponsored by the Nuffield Trust (London) and the Commonwealth Fund (New York City), and the first of a series of meetings began at Ditchley Park in Oxfordshire in the summer of 1999. The Ditchley meetings and the work by joint US/UK teams in between led to a formal cooperative agreement being signed between the governments in 2001 .

This initiative and everything that has and will continue to flow from it is just one of many enduring legacies left by this uniquely gifted man. His friends in the UK will always be grateful for being part of John Eisenberg's journey.

\section{Sir Liam Donaldson \\ Chief Medical Officer, Department of Health, London SWIA 2NS, UK liam.donaldson@doh.gsi.gov.uk}

John Eisenberg was noble. Of course, anyone who had said that in his presence would have been treated to a graceful, self-deprecating, and very funny reply from John. But, it would not have changed my mind or the opinion of anyone else who had the privilege to know and work with him. He was noble, and he ennobled both his discipline and his colleagues.

He was denied his full measure of years, but in his shortened life he accomplished more in several fields than most of us could imagine achieving in one field. John changed the face of health services research worldwide. He made and participated in fundamental intellectual contributions in decision analysis, technology assessment, health care economics, medical education, and clinical epidemiology, to name a few. No one was his equal in understanding and articulating the big picture, strategic view of how health care evaluation, quality, and knowledge can and should progress. He built bridges among disciplines, and had a rare and instructive capacity to work well at intersections. John connected things. He connected us.

But no one who knew John can regard his contributions as only ones of intellect. What he gave and modeled was also a form of gracefulness and helpfulness that touched not only minds but lives. He acknowledged encouraged, and worked with the best in each of us, and he seemed incapable of pettinessincapable of weakening the energy or selfesteem of others. I smile to remember the first moments of meetings, usually chaired by John-because he was usually the "obvious" chair-with 20 or 30 people around the table. Most of us would have taken the easy way, asking people to introduce themselves. Not John. He would himself embrace the tableeach person-with his warmth and his words, somehow always finding a fond memory or shared accomplishment to describe to all of us about each of us, as if in some compartment of his generous mind he had stored up an endless list of good and happy stories-as if somehow, incredibly, he knew everyone everywhere, and liked them. He left us laughing.

He was relentlessly, authentically curious. The easiest way I knew to find the next good book to read was to ask John what was last on his nightstand. His mind was of the type addicted to search, learning better from the unfamiliar than from the usual. In this, he modeled humility since he, better than most, had the self-confidence to ask real questions to which he did not at the start know the answer. No Socratic method for John. No false questions, only true ones.

I took an ambulance ride to keep John company. Though slightly sedated and more 
than a little ill, John spent the whole time quizzing the young EMT on his opinions about the patient safety movement, how he was trained, whether he was supported well enough to report hazards and errors, and what ideas he had to improve emergency care. Had the ride been a few minutes longer, I am sure John would have co-authored a paper with him. Just as John was constitutionally supportive of others, he was constitutionally inquisitive.

To say we-I-will miss John is only a pale image of the truth. He was a compass for our thoughts, a model for our values, and a tonic for our souls. In his absence we will all have to try much harder to find the right way.

Donald M Berwick

Institute for Healthcare Improvement 375 Longwood Avenue, 4th Floor, Boston, MA 02215 USA; eharrington@ihi.org

I first met John Eisenberg when he came to the Hospital of the University of Pennsylvania in 1972 to begin a residency in internal medicine. It was clear to all of us who directed the program that John was a special person. He quickly distinguished himself among a talented peer group, but then moved even further beyond his peers by deciding to devote his professional career to health services research and to the nascent field of primary care general internal medicine.

John's first interest in those new disciplines was kindled as a Princeton undergraduate by contact with Herman and Anne Somers, and as a medical student at Washington University in St Louis by studying with the health services research pioneer, Dr Gerald Perkoff. But it was not until he came to Penn that he had the chance to work with other scholars with similar interests and to prepare himself for a new kind of academic career. At Penn, after several years of post-residency training, he was asked to help establish a genera medicine unit. Still at Penn, he then went on to become the chief of what developed into one of the most outstanding centers of research and teaching in the field.

John's enthusiasm was contagious. Together with his high energy and intelligence, it quickly made him a leader in general medicine to which he contributed many valuable research studies. He also soon became one of the most respected figures in the new national organizations promoting health services research and scholarship in the field of primary care.

He subsequently distinguished himself as one of the first of the new generation of academic scholars in his field to be appointed to a major Chair in Medicine (at Georgetown) and to be elected to membership in the Institute of Medicine and the Association of American Physicians. His appointment to be Director of the Agency for Health Care Policy and Research (now called the Agency for Healthcare Research and Quality) was the logical next step in a steadily rising career. It signified that John was likely to play a key role in shaping policy for the future US healthcare system. Under his direction AHCPR got off to a highly promising start. That his career has been brought to a sudden and premature end by a brain tumor is a tragedy not only for his family and friends but for his many colleagues in medicine and for the country as a whole. Despite all his accomplishments, one had the sense that when he died at the age of 55 there were still greater contributions in the offing. People with John's talents are much needed these days, but they are very rare. He was a good man and a fine physician who was deeply committed to the improvement of health care in the US. He will be greatly missed.

Arnold S Relman

Professor, Harvard Medical School, 181 Longwood Avenue, 5th Floor Boston MA 02 1 15-5804, USA; arelman@rics.bwh.harvard.edu

John Eisenberg was an extraordinary leader doctor, teacher and friend. His death is a great loss to the healthcare community. Today's healthcare system has been shaped by his efforts to ensure a closer link between scientific research and health policy, management, and clinical decisions.

However, John's influence will continue to grow as those to whom he was advisor, friend, and mentor continue to develop in their careers. John was a truly extraordinary mentor. While many teachers can rightfully claim to have inspired people, Sandy Schwartz, MD, from the University of Pennsylvania, observed: "A list of the nation's most respected and productive health services researchers is notable for the disproportionate number for whom John has been a mentor, advisor, close colleague and friend".

He was passionate about helping others grow professionally. As chief of General Internal Medicine at the University of Pennsylvania and Chair of Medicine at Georgetown University, John would make time to counsel medical students and residents while forcing senior clinicians to wait. John remembered the research interests of those with whom he worked and frequently sent copies of relevan articles to individuals with a note suggestin how it might be incorporated into their work.

John had a file folder for each of us who worked with him closely. That file folder contained rough outlines of papers on which we were working. Whenever we met with him, regardless of the purpose of the meeting, that folder emerged and he would ask about the status of each project, gently prodding us to complete the papers. I have publications on my resume that would not have been there if not for his guidance, prodding, and confidence in my abilities.

In the early 1990s the Robert Wood Johnson Foundation asked John to serve as the Director of the Generalist Physician Faculty Scholars Program. His delight in furthering the careers of some of the nation's most talented academic generalists was readily apparent. He met with or talked to the faculty scholars at every opportunity and helped them find career paths leading to greater success. He believed that they could accomplish far more than they did and inspired them to reach higher.

One did not have to work with John to get the benefit of his insights. Former students and colleagues, people with whom he served on committees, and people who met John at conferences would send him drafts of papers. He would read and comment on all of them, suggesting additional articles that they should read and incorporate or asking critica questions about points in the article.

The loss of John Eisenberg is more than just the loss of an insightful health policy maker researcher and clinician. I will miss him as many will as they have lost a trusted friend and mentor.

Nancy Foster

Coordinator for Quality Activities, AHRQ, 210 East Jefferson Street, Rockville, MD 20852, USA nfoster@ahrq.gov 